\title{
THE ANALYSIS OF CYANIDE SILVER-PLATING SOLUTIONS
}

\author{
By R. M. Wick
}

\section{ABSTRACT}

Methods for the analysis of cyanide silver-plating solutions were studied, including the determination of free cyanide, total cyanide, carbonate, chloride, ammonia, silver, iron, copper, and mercury. Electrometric titrations showed that the Liebig method for alkali cyanide is correct to better than 0.2 per cent. Addition of iodide makes the method still more accurate and overcomes the effects of impurities on the titration.

The nonagreement of the Liebig and Hannay methods was studied by electrometric titrations, which showed that the visual Hannay method gives high results although the electrometric Hannay titration is accurate. The determination of total cyanide was accomplished by distillation with sulphuric acid, and of total effective cyanide by titration with iodine.

Silver may be separated as silver sulphide, by precipitation with zinc, or by decomposition with acid, after which a determination by any standard method is applicable.

Carbonate may be determined by precipitating and filtering out barium carbonate and titrating it with acid or by titrating a sample with acid after adding silver nitrate to combine with the free cyanide.

The usual method for the determination of chloride involves prolonged treatment with nitric acid, which converts the precipitated silver cyanide to silver chloride. A new method for separating chloride was investigated in which the silver is precipitated as sulphide and the iron is removed by precipitation as manganous ferrocyanide. The chloride in the filtrate can be determined by the usual methods.

Iron and copper can be determined by the regular analytical methods after decomposition of the plating solution with sulphuric acid. Mercury can be determined by precipitation as sulphide along with silver sulphide. The mercuric sulphide is extracted from the mixed sulphide precipitate with sodium hydroxide, reprecipitated, and weighed.

A new method was developed for the determination of ammonia in cyanide solutions, in which the free cyanide is converted to the silver complex preparatory to the usual distillation. Direct distillation is not satisfactory because ammonia is formed by decomposition of alkali cyanide at elevated temperatures.

\section{CONTENTS}

I. Introduction

II. Composition of silver-plating solutions

III. Analytical methods

1. Cyanide

A. Alkali cyanide

(1) Titration of pure solutions

(a) Liebig method

(b) Electrometric method

(c) Liebig titration with iodide present.-

(d) Comparison of Liebig and Hannay methods... 918

(2) Effect of impurities on the Liebig titration.-

(a) Alkali hydroxide.

(b) Alkali carbonate...

(c) Chloride.

(d) Ammonia

(e) Ferrocyanide...

D. Total effective cyanide 
II. Analytical methods-Continued.

2. Silver

A. Separation from the cyanide

(1) Precipitation of silver.

(a) As sulphide

(b) As silver

(2) Decomposition of the cyanide

B. Determination of silver.

(1) Volhard titration

(2) Precipitation as silver chloride

(3) Electrolytic determination

C. Comparison of methods

3. Carbonate.

A. Barium carbonate method .

4. Chloride

B. Titration after addition of silver nitrate.

5. Iron, copper, and mercury

6. Ammonia .

IV. Recommended procedures

1. Free cyanide.

2. Total cyanide.

3. Total effective cyanide

4. Silver

5. Carbonate

6. Chloride

7. Iron, copper, and mercury

A. Iron

B. Copper.

8. Ammonia

C. Mercury

V. Acknowledgment

\section{INTRODUCTION}

Much of the recent progress in the electroplating industry is due to the more general use of chemical analysis for the control of the solutions. High accuracy is usually not required, but it is important to know whether the methods that have been proposed or used yield results of the desired reliability in the presence of all the probable constituents, including impurities. In research work a higher degree of accuracy is sometimes needed. In the following study of silverplating solutions both of these requirements have been considered, in the effort to develop control methods that are correct to at least 2 per cent and research methods accurate to 0.2 per cent.

As the methods for the determination of cyanide are most important in silver-plating baths and as they have been questioned in the literature, they were given special consideration, and their accuracy was determined by comparison with electrometric methods. In general, volumetric methods were investigated, as they are more convenient for control purposes.

\section{COMPOSITION OF SILVER-PLATING SOLUTIONS}

All commercial silver plating is done in cyanide solutions, from which relatively dense fine-grained deposits are secured, in contrast with the coarse deposits obtained from silver nitrate solutions, which are used for silver refining. Modern plating baths are prepared by dissolving silver cyanide in either potassium or sodium cyanide, the former being more commonly used. All methods of analysis, and hence the following discussions, apply equally to the potassium or sodium salts. 
The principal constituent of the baths is potassium argentocyanide, $\mathrm{KAg}(\mathrm{CN})_{2}$. The baths contain an excess of the alkali cyanide, which is known as the "free cyanide." Commercial solutions are about $0.25 \mathrm{~N}$ with respect to both silver and free cyanide. In addition they invariably contain alkali carbonate, which is sometimes added in the preparation of a new bath. In any case it forms in the solution by decomposition of the cyanide, and may accumulate to high concentrations. During the decomposition of cyanides, ammonia is usually formed, and hence is present in all used cyanide solutions. Its concentration is not likely to be high, as at the high $\mathrm{pH}$ of these solutions the ammonia is free and rapidly volatilizes, especially at elevated temperatures.

In former years the baths were made from silver chloride, and hence contained much alkali chloride. Some chloride is present in all commercial baths as a result of impurities in the chemicals or the water used. The baths are likely to contain iron, present as ferrocyanide. This enters from corrosion of the steel tanks, pipes, or hangers, especially if much chloride is present. Small amounts of copper may be introduced from the preceding "strike" solutions, to which copper is added, or from corrosion of the copper tank bars. Mercury may be introduced, especially into the strike solution, if mercury dips are used prior to silver plating. As mercury dips are now seldom used, such contamination is improbable.

For control the most common determinations are those for free cyanide and silver. Carbonate is occasionally determined, though the bath is not sensitive to small changes in the carbonate concentration. In this investigation the analytical methods for these three substances were examined, and the effects of other constituents upon the results were determined. Methods for estimating impurities were also studied.

Prior to the regular silver plating it is customary to apply flash coats of silver from "strike solutions." These generally have a high content of free cyanide and a low content of silver. In some cases copper is added to the strikes. In general the same methods of analysis are applied to the strikes as to the regular solutions, although the composition of the strikes is less critical.

\section{ANALYTICAL METHODS}

\section{CYANIDE}

\section{A. ALKALI CYANIDE}

As it is sometimes desirable to analyze the alkali cyanide used in the preparation of silver baths and as the free cyanide determination involves the titration of alkali cyanide, the methods for this determination were first investigated.

(1) Titration of Pure Solutions.- - (a) Liebig method.-Titration with silver nitrate, usually attributed to Liebig (1), ${ }^{1}$ is most commonly used, either in its original form or with the addition of iodide. The accuracy of the Liebig method was questioned by Frary and Porter (2) because it gave lower results than the Hannay (mercuric chloride) titration. Thompson (3) prepared very pure potassium cyanide and with it showed that the Hannay method gives high results, and that

1 Numbers in the text refer to the bibliography $a_{0}$, ihe end of the paper. 
the Liebig method is more accurate. Additional confirmation of the latter method was obtained in this investigation.

In the Liebig method (1) silver nitrate is added to a solution of alkali cyanide until reaction 1 ,

$$
2 \mathrm{KCN}+\mathrm{AgNO}_{3}=\mathrm{KAg}(\mathrm{CN})_{2}+\mathrm{KNO}_{3}
$$

is complete. On further addition of silver nitrate, reaction 2 ,

$$
\mathrm{KAg}(\mathrm{CN})_{2}+\mathrm{AgNO}_{3}=2 \mathrm{AgCN}+\mathrm{KNO}_{3}
$$

begins, and results in the formation of insoluble silver cyanide. The appearance of the latter as an opalescence serves as the end point of reaction 1 .

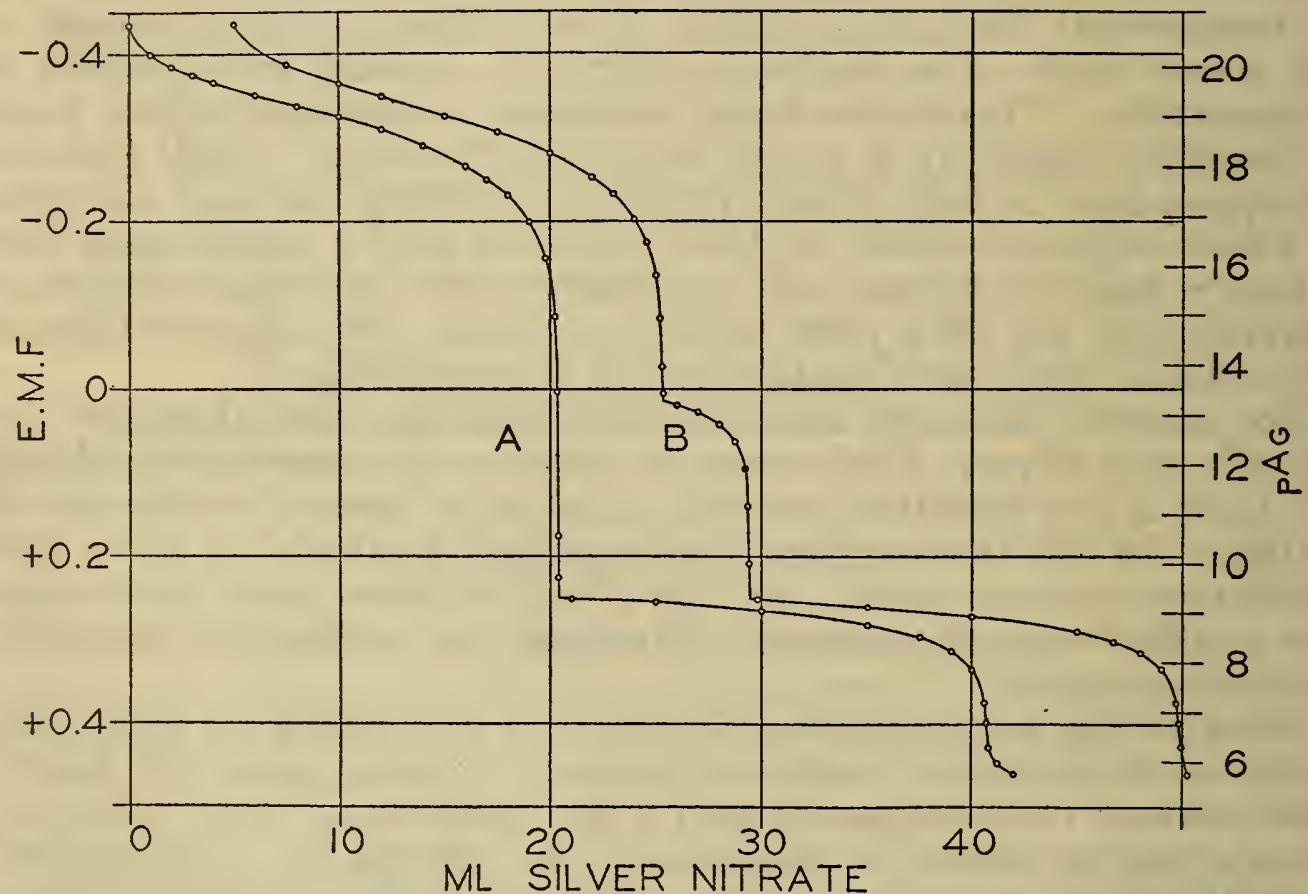

FIGURE 1.-Electrometric titration of potassium cyanide with $0.1 \mathrm{~N}$ silver nitrate

A, Without potassium iodide.

$\mathrm{B}$, With potassium iodide.

(The origin of curve B is displaced $5 \mathrm{ml}$ to the right of $\mathrm{A}$.) 3 ,

When potassium iodide is present in the titrated solution, reaction

$$
\mathrm{KI}+\mathrm{AgNO}_{3}=\mathrm{AgI}+\mathrm{KNO}_{3}
$$

takes precedence over reaction 2 because the solubility of silver iodide is lower than that of silver cyanide. The appearance of silver iodide is then taken as the end point of reaction 1 .

(b) Electrometric method.-As the above reactions involve the formation or removal of silver ions, their course may be followed electrometrically by using a silver electrode. The theory of the electrometric titration is discussed by Kolthoff and Furman (4). The application of the silver electrode to cyanide solutions was reported by W. D. Treadwell (5) and later by Müller and Lauterbach (6).

Curve A of Figure 1 shows the course of a typical titration made in this investigation, in which the potential of the silver electrode $\left(E_{n}\right)$ 
(or the corresponding $\mathrm{pAg})^{2}$ is plotted against the volume of $0.1 \mathrm{~N}$ silver nitrate added to $20 \mathrm{ml}$ of approximately $0.2 \mathrm{M}$ sodium cyanide. In this curve the first inflection marks the end of reaction 1 and the second the end of reaction 2. These two points of inflection were defined more closely by completing the titration with $0.01 \mathrm{~N}$ silver nitrate when they were approached. The results are shown in Figure $2, A$ and $B$, in which the points of inflection are defined by plotting $\Delta E$

$\frac{\Delta E}{\Delta V}$, that is, the rate of change of potential with the volume of reagent against the volume. It is evident that the second point of inflection is less sharp than the first, but both are readily defined.
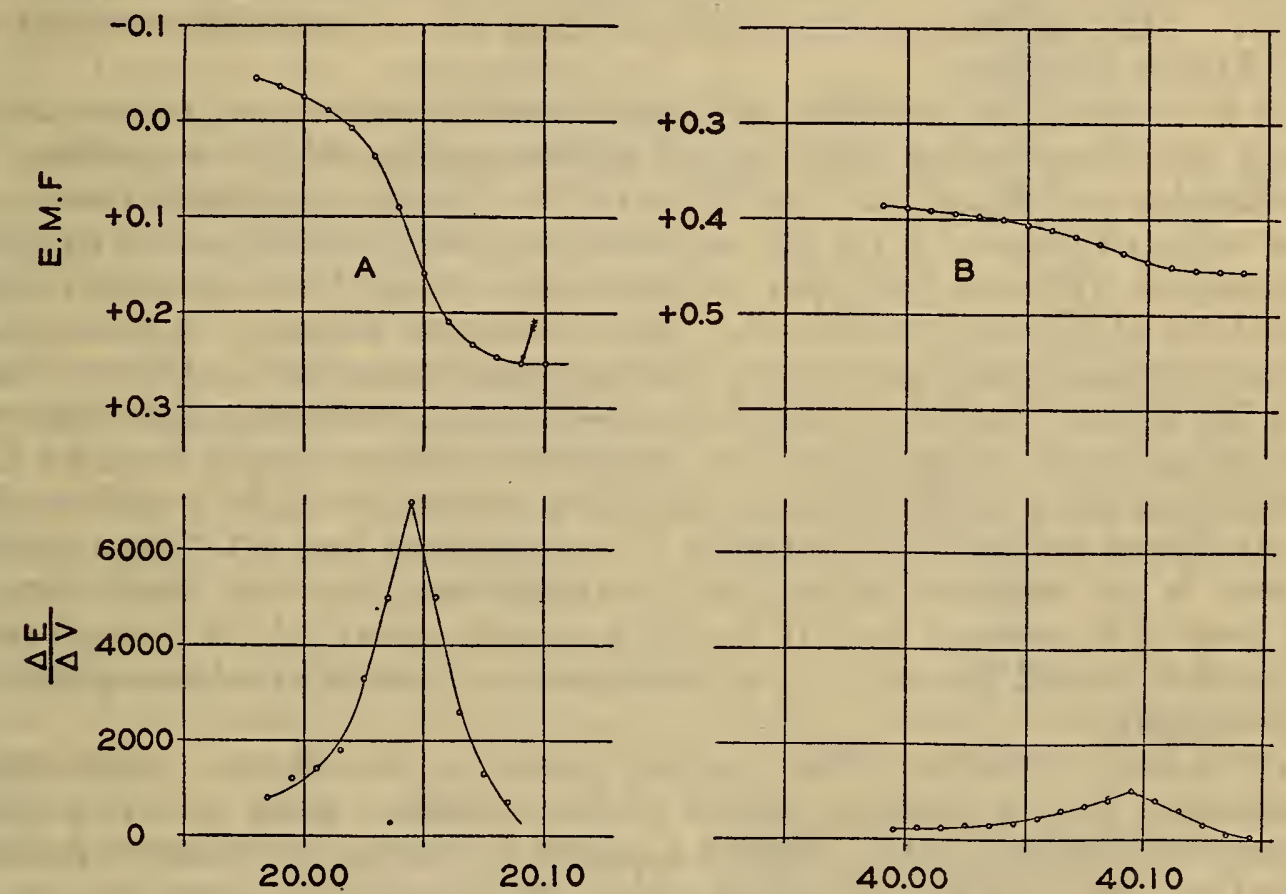

MILLILITERS

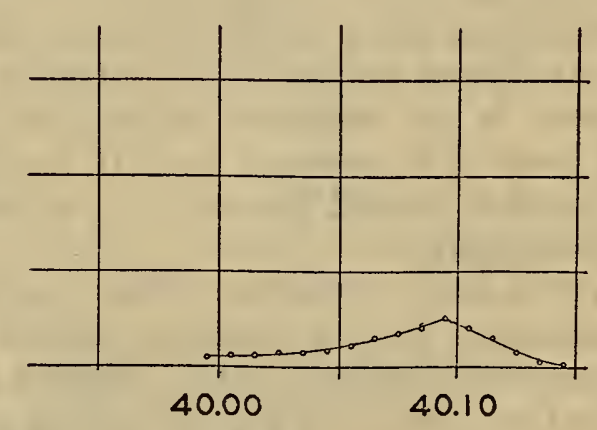

FIGURE 2.-Points of inflection in electrometric titration of potassium cyanide without iodide, using $0.01 \mathrm{~N}$ silver nitrate near the end points

\section{A, First inflection. \\ $\mathrm{B}$, Second inflection.}

TABLE 1.-Ratio of end points in electrometric titration of alkali cyanide

\begin{tabular}{|c|c|c|c|}
\hline \multirow{2}{*}{ Experiment No. } & \multicolumn{2}{|c|}{ Volume of $0.1 \mathrm{NAgNO}_{3}$} & \multirow{2}{*}{ Ratio } \\
\hline & First & Second & \\
\hline $\begin{array}{l}40 \\
41\end{array}$ & \multirow[t]{2}{*}{$\begin{array}{l}m l \\
20.35 \\
20.05 \\
19.85 \\
20.40\end{array}$} & \multirow[t]{2}{*}{$\begin{array}{c}m l \\
40.70 \\
40.05 \\
39.70 \\
40.84\end{array}$} & $\begin{array}{l}2.000 \\
1.998 \\
2.000 \\
2.002\end{array}$ \\
\hline Average. & & & 2.000 \\
\hline
\end{tabular}

If these two points represent accurately the end points of reactions 1 and 2, the volume of silver nitrate required for the second point

${ }^{2} \mathrm{pAg}$, the negative logarithm of the silver ion activity, is analogous to $\mathrm{pH}$. 
should be twice that for the first. In Table 1 are shown the results of several electrometric titrations made from time to time. The close agreement of this ratio with the theoretical value is strong evidence that the reactions proceed exactly according to the equations. A previous publication (6) reported a deviation of 0.5 per cent in this ratio, but in this case only $10 \mathrm{ml}$ of silver nitrate was used, and accordingly the precision was probably not much greater than the reported discrepancy.

As shown in Figure $2 \mathrm{~A}$, the visual precipitation (marked by an arrow) of silver cyanide does not exactly coincide with the first point of inflection, though the discrepancy is only about $0.04 \mathrm{ml}$ of $0.1 \mathrm{~N}$ $\mathrm{AgNO}_{3}$, equivalent to 1 part in 500 if $20 \mathrm{ml}$ of titrating solution be used. This difference does not invalidate the substantial accuracy of the Liebig titration.

It is possible to calculate an equivalence point for argentocyanide from the dissociation constant of the complex, which according to Bodländer and Eberlein (7) is $8.8 \times 10^{-22}$. Such a calculation leads to the value of $\mathrm{pAg}=7.8$ for the equivalence point, which is not in good agreement with the first point of inflection at $\mathrm{pAg} 11.0$ computed from the data of Figure 2 , curve A. The silver ion activity at which the silver cyanide precipitates may be computed from its solubility product (8) (9) as pAg 9.3, which is in close agreement with the observed precipitation at $\mathrm{pAg}$ 9.4. The calculated values would lead to the prediction that silver cyanide should precipitate slightly before the equivalence point, while actually it precipitates just after that point. There is no entirely satisfactory explanation for this discrepancy. At least it is evident that if $\mathrm{AgCN}$ precipitates at $\mathrm{pAg} 9.3$, such precipitation would prevent the establishment of an equivalence point at a lower $\mathrm{pAg}$.

(c) Liebig titration with iodide present.-As above mentioned, potassium iodide is often added to the solution prior to the Liebig titration (Denigès, 10). Figure 1 , curve $B$, shows the effect of iodide. The first break in the curve coincides with the initial precipitation of silver iodide, at a slightly lower silver ion activity (higher $\mathrm{pAg}$ ) than that at which silver cyanide precipitates, the second break in curve B, and at a point which approaches very closely to the measured equivalence point. It is evident, therefore, that the titration with iodide yields a more accurate result than the visual Liebig method. In pure solutions the difference is negligible, but, as will be shown, the iodide is especially effective in titrating contaminated solutions.

(d) Comparison of Liebig and Hannay methods.-A comparison between the Liebig and Hannay methods was made electrometrically. For the latter method the potential of a mercury electrode was measured during the addition of mercuric chloride to the solution, which contained a small amount of ammonia. In this titration the first reaction is

$$
4 \mathrm{KCN}+\mathrm{HgCl}_{2}=\mathrm{K}_{2} \mathrm{Hg}(\mathrm{CN})_{4}+2 \mathrm{KCl}
$$

At the end point any excess of mercuric chloride reacts with the ammonia to form a white precipitate

$$
\mathrm{HgCl}_{2}+2 \mathrm{NH}_{4} \mathrm{OH}=\mathrm{NH}_{2} \mathrm{HgCl}+\mathrm{NH}_{4} \mathrm{Cl}+2 \mathrm{H}_{2} \mathrm{O}
$$

In Figure 3 is shown the relation between the Hannay $(A)$ and Liebig $(B)$ titrations near the end points. The volumes of the 
respective reagents consumed at the inflection points agree within 0.2 per cent with the equivalence, represented by the line $E$. However, the precipitation of silver cyanide occurs at the point $C$, which coincides closely with $E$, while that of the mercury compound occurs at $D$, which is several per cent beyond $E$. These results show clearly that reaction (4) of the Hannay method is quantitative, but that the visual end point, as defined by reaction (5), is seriously in error. The observed discrepancy between the two methods with visual end points is thus fully accounted for.

(2) Effects of Impurities oN the Liebig Titration.-The effects upon the cyanide titration produced by probable impurities in the silver baths were next investigated. In the following tables the amounts of alkali cyanide "present" are based on electrometric determinations with no impurities present. In all cases the data are representative of those obtained in two or more concordant experiments.

(a) Alkali hydroxide.-While alkali hydroxide is rarely present in silver baths, its addition to samples prior to the Liebig titration has been suggested. As shown in Table 2, large amounts of hydroxide produce marked errors in the Liebig titration, which, however, are completely eliminated by the addition of iodide.

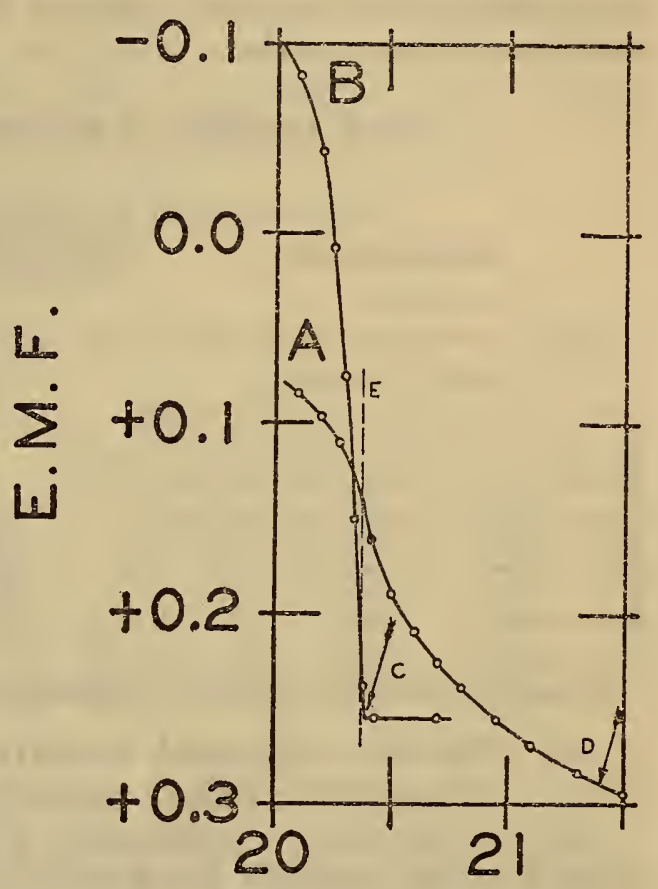

\section{MILLILITERS}

FIGURE 3.-Electrometric comparison of Liebig and Hannay titrations

A, Hannay titration with mercuric chloride.

B, Liebig titration with silver nitrate.

C, Precipitation of silver cyanide.

D, Precipitation of mercury compound.

E, Equivalence point.

These results confirm the statements of Clennell (11) and Sharwood (12).

TABLE 2.-Effect of $\mathrm{NaOH}$ on Liebig titration

\begin{tabular}{|c|c|c|c|c|c|}
\hline \multirow{2}{*}{ Experiment No. } & \multirow{2}{*}{$\frac{\mathrm{mol} \mathrm{NaOH}}{\mathrm{mol} \mathrm{NaCN}}$} & \multirow{2}{*}{$\mathrm{KI}$} & \multicolumn{2}{|c|}{$\mathrm{NaCN}$} & \multirow{2}{*}{ Error } \\
\hline & & & Present 1 & Found & \\
\hline 5 & $\begin{array}{r}0 \\
10 \\
10 \\
10 \\
10\end{array}$ & $\begin{array}{c}g \\
0.04 \\
.04\end{array}$ & $\begin{array}{c}g \\
0.1976 \\
.1974 \\
.1976 \\
.1976 \\
.1975\end{array}$ & $\begin{array}{l}g \\
0.1980 \\
.2074 \\
.2075 \\
.1978 \\
.1977\end{array}$ & $\begin{array}{r}\text { Per cent } \\
+0.20 \\
+5.06 \\
+5.01 \\
+.10 \\
+.10\end{array}$ \\
\hline
\end{tabular}

1 Based on electrometric end point with no additions.

(b) Alkali carbonate.-Table 3 shows that high concentrations of carbonate, probably greater than are present in a silver bath, produce an error in the Liebig titration of less than 1 per cent. (The carbonate has no effect on the electrometric end point.) The effect of 
carbonate is completely overcome by the use of iodide, as previously noted by Clennell (11), Sharwood (12), and Sanigar (13). As shown by the last author, the tendency of carbonate to cause the formation of a difficultly soluble granular precipitate which obscures the true end point, can be minimized by dilution, or by the addition of a small amount of ammonia.

TABLE 3.-Effect of sodium carbonate on the Liebig titration

\begin{tabular}{|c|c|c|c|c|c|c|}
\hline \multirow{2}{*}{ Experiment No. } & \multirow{2}{*}{$\frac{\mathrm{mol} \mathrm{Na}_{2} \mathrm{CO}_{8}}{\mathrm{~mol} \mathrm{NaCN}}$} & \multirow{2}{*}{$\mathrm{Na}_{2} \mathrm{CO}_{3}$} & \multirow{2}{*}{$\mathbf{K I}$} & \multicolumn{2}{|c|}{$\mathrm{NaCN}$} & \multirow{2}{*}{ Error } \\
\hline & & & & Present & Found & \\
\hline $\begin{array}{l}{ }^{2} \\
{ }^{2}\end{array}$ & $\begin{array}{l}0 \\
.1 \\
.1 \\
1 \\
1 \\
10 \\
10 \\
10 \\
10\end{array}$ & \begin{tabular}{l}
$g / l 1$ \\
\hdashline 2.65 \\
2.65 \\
26.5 \\
26.5 \\
26.5 \\
26.5 \\
26.5 \\
26.5
\end{tabular} & $\begin{array}{c}g \\
\\
\\
0.04 \\
04\end{array}$ & $\begin{array}{r}g \\
0.2005 \\
.2006 \\
.1995 \\
.1991 \\
.1976 \\
.1990 \\
.1995 \\
.1996 \\
.2001\end{array}$ & $\begin{array}{l}g \\
0.2009 \\
.2010 \\
.1999 \\
.1998 \\
.1984 \\
.2006 \\
.2010 \\
.1996 \\
.2000\end{array}$ & $\begin{array}{r}\text { Per cent } \\
+0.20 \\
+.20 \\
+.20 \\
+.35 \\
+.40 \\
+.80 \\
+.75 \\
0 \\
-.05\end{array}$ \\
\hline
\end{tabular}

1 Concentration expressed in terms of plating solution.

(c) Chloride.-Several experiments indicated that alkali chloride has no appreciable effect on the Liebig titration.

(d) Ammonia.-Ammonia, which may be present in the bath or added to the sample for analysis (10), (11), (12), has a solvent action on silver compounds and tends to maintain a clear solution up to the desired end point. Large additions cause gross errors in the visual Liebig end point, but within certain limits the presence of iodide eliminates this effect of ammonia. However, according to Treadwell (5), a large excess of ammonia dissolves silver iodide and yields high results. These observations are all confirmed in Table 4. The fact that the silver electrode potential at equivalence is more negative in the presence of ammonia, indicates that the latter has reacted with the argentocyanide to form a still less dissociated compound. When the ammonia is more than equivalent to the cyanide, the second electrometric end point vanishes.

TABLE 4.-Effect of ammonium hydroxide on the Liebig titration

\begin{tabular}{|c|c|c|c|c|c|c|c|c|c|}
\hline \multirow{4}{*}{ Experiment No. } & \multirow{4}{*}{$\frac{\mathrm{mol} \mathrm{NH}_{4} \mathrm{OH}}{\mathrm{mol} \mathrm{NaCN}}$} & \multirow{4}{*}{$\mathrm{NH}_{4} \mathrm{OH}$} & \multirow{4}{*}{$\mathbf{K I}$} & \multicolumn{6}{|c|}{$\mathrm{NaCN}$} \\
\hline & & & & \multirow{3}{*}{ Present } & \multicolumn{5}{|c|}{ Found } \\
\hline & & & & & \multicolumn{3}{|c|}{ Electrometric } & \multicolumn{2}{|c|}{ Liebig } \\
\hline & & & & & $\begin{array}{c}\text { Equiv- } \\
\text { alence } \\
\text { potential } \\
E_{\mathrm{A}}\end{array}$ & & Error & & Error \\
\hline & \begin{tabular}{l|l}
0 \\
0.1 \\
1 \\
10 \\
1 \\
10
\end{tabular} & $\begin{array}{r}g / l 1 \\
0.9 \\
8.8 \\
87.6 \\
8.8 \\
87.6\end{array}$ & $\begin{array}{c}g \\
0.04 \\
.04\end{array}$ & $\begin{array}{r}0.1977 \\
.1976 \\
.1971 \\
.1975 \\
.1951 \\
.1999\end{array}$ & $\begin{array}{r}+0.161 \\
+.106 \\
+.034 \\
-.034 \\
\end{array}$ & $\begin{array}{c}g \\
0.1977 \\
.1970 \\
.1963 \\
.1961 \\
.1951 \\
.1938\end{array}$ & $\mid$\begin{tabular}{c} 
Per cent \\
0 \\
-0.3 \\
-.4 \\
-.7 \\
\hdashline
\end{tabular} & $\begin{array}{c}g \\
0.1981 \\
.1984 \\
.2037 \\
.2705 \\
.1956 \\
.2006\end{array}$ & $\begin{array}{c}\text { Per cent } \\
+0.2 \\
+.35 \\
+3.5 \\
+37.0 \\
+.3 \\
+.3\end{array}$ \\
\hline
\end{tabular}

1 In terms of plating solution. 
(e) Ferrocyanide.-It has been reported (5), (11), (12), that ferrocyanides cause high results in the Liebig titration and that iodide prevents this error. The ferrocyanide also fosters the formation of a curdy precipitate that redissolves slowly. The results in Table 5 show that the presence of sufficient iodide eliminates the effect of ferrocyanide in concentrations that are likely to be present in silver plating baths. Unless considerable iodide is present, very large amounts of the ferrocyanide still cause an appreciable error.

TABLE 5.-Effect of ferrocyanide on Liebig titration

\begin{tabular}{|c|c|c|c|c|c|c|}
\hline \multirow{2}{*}{ Experiment No. } & \multirow{2}{*}{$\mathrm{Na} a_{4} \mathrm{Fe}(\mathrm{CN})_{0}$} & \multirow{2}{*}{$\mathrm{Fe}$} & \multirow{2}{*}{ KI } & \multicolumn{2}{|c|}{$\mathrm{NaCN}$} & \multirow{2}{*}{ Error } \\
\hline & & & & Present & Found & \\
\hline $\begin{array}{l}2 \\
2\end{array}$ & $\begin{array}{cr}\text { g/l1 } & \\
& 0 \\
& 20 \\
& 20 \\
& 38 \\
& 38 \\
& 78 \\
& 78 \\
& 78 \\
& 76 \\
& 61\end{array}$ & $\begin{array}{l}g / l 1 \\
0 \\
3.7 \\
3.7 \\
7.0 \\
7.0 \\
14.5 \\
14.5 \\
14.0 \\
11.2\end{array}$ & $\begin{array}{l}0.04 \\
.04 \\
.04 \\
.04 \\
.04 \\
.04 \\
.04 \\
.25 \\
.25\end{array}$ & $\begin{array}{l}g \\
0.2186 \\
.1948 \\
.1875 \\
.2134 \\
.1852 \\
.1978 \\
.1875 \\
.1985 \\
.2487\end{array}$ & $\begin{array}{l}g \\
0.2186 \\
.1953 \\
.1875 \\
.2140 \\
.1857 \\
.1986 \\
.1885 \\
.1986 \\
.2487\end{array}$ & $\begin{array}{c}\text { Per cent } \\
0 \\
+0.25 \\
0.0 \\
+.27 \\
+.27 \\
+.40 \\
+.53 \\
+.05 \\
0\end{array}$ \\
\hline
\end{tabular}

1 In terms of plating solution.

\section{B. FREE CYANIDE}

The term "free cyanide" in electroplating has usually been defined as the excess of alkali cyanide above the amount required to form some complex, such as $\mathrm{KAg}(\mathrm{CN})_{2}$. For silver solutions this definition is satisfactory, because $(a)$ the silver complex is definite, and $(b)$ the titration with silver nitrate in the presence of iodide yields results that correspond closely to this compound.

As above noted, the silver plating solutions contain only one stable complex, $\mathrm{KAg}(\mathrm{CN})_{2}$, which is also formed during the titration of alkali cyanide with silver nitrate. The only essential difference therefore between a silver solution containing free cyanide and a partly titrated solution of alkali cyanide, is that the latter contains a quantity of alkali nitrate equivalent to the silver nitrate added. Numerous observations here and elsewhere have shown that such an amount of nitrate has no measurable effect on the titration. Sanigar (13) found that the addition of over $7 \mathrm{~g}$ of potassium nitrate produced an error of only 1 part in 400 in the Liebig titration of $10 \mathrm{ml}$ of 0.5 $M \mathrm{KCN}$. As this content of nitrate was about 300 times that formed in the titration, it is evident that the latter amount can have no significant effect.

It is obvious, therefore, that all the data obtained in the titration of alkali cyanide apply directly to the determination of free cyanide in silver-plating solutions, and that by the addition of iodide the effects of all probable impurities upon the titration can be effectively eliminated.

\section{TOTAL CYANIDE}

Most of the heavy-metal impurities in a silver bath exist as double cyanides, such as $\mathrm{K}_{2} \mathrm{Cu}(\mathrm{CN})_{3}, \mathrm{~K}_{2} \mathrm{Hg}(\mathrm{CN})_{4}$, and $\mathrm{K}_{4} \mathrm{Fe}(\mathrm{CN})_{6}$. The "total cyanide" includes that present in all such compounds plus that in $\mathrm{KAg}(\mathrm{CN})_{2}$ and the free $\mathrm{KCN}$. For pure silver solutions it is possible to compute the content of total cyanide, which is the sum of 
the free cyanide and that combined with the determined content of silver. For contaminated solutions such calculations are of doubtful value because of possible errors in the determination of all the metals present, and of uncertainty as to the composition of the corresponding complex cyanides.

For many cyanide solutions, including those of silver, distillation with sulphuric acid followed by absorption and titration of the evolved hydrocyanic acid, yields fairly reliable results for total cyanide. In silver plating the determination of total cyanide is of interest chiefly for research purposes. The distillation method is applicable to other cyanide plating baths, and may be of value in the control of zinc or brass baths, in which the free cyanide is less readily determined.

Distillation is carried out after the addition of about $250 \mathrm{ml}$ of water and $10 \mathrm{ml}$ of $1: 1$ sulphuric acid, and continued until the precipitate formed on acidification has dissolved and at least half of the solution has distilled over. When chloride is present in the plating solution a residue of insoluble silver chloride persists which makes difficult the detection of complete decomposition, but does not otherwise cause error. Complete recovery of cyanide from ferrocyanide is not possible by acid treatment unless other metals are present which form readily decomposible ferrocyanides. Additions of copper as cuprous chloride was suggested by H. E. Williams (14) as the basis of a method for estimating ferrocyanides. In the present investigation it was found that equally good results are obtainable when complex silver cyanide is present, so that addition of a cuprous salt to the sample is not essential. When alone, cuprous cyanide requires the presence of a chloride (or hydrochloric acid) to complete its decomposition, but in the presence of ferrocyanide no chloride is needed. In silver-plating solutions it is not necessary to add a chloride to decompose any copper cyanide that may be present, as the commercial solutions invariably contain some ferrocyanide.

TABLE 6.-Determination of total cyanide by distillation and titration

\begin{tabular}{|c|c|c|c|c|}
\hline \multirow{2}{*}{$\begin{array}{c}\text { Experi- } \\
\text { ment } \\
\text { No. }\end{array}$} & \multirow{2}{*}{ Constituents of sample } & \multicolumn{3}{|c|}{ Cyanides (CN) } \\
\hline & & Present & Found & Error \\
\hline 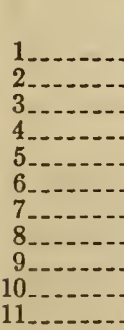 & 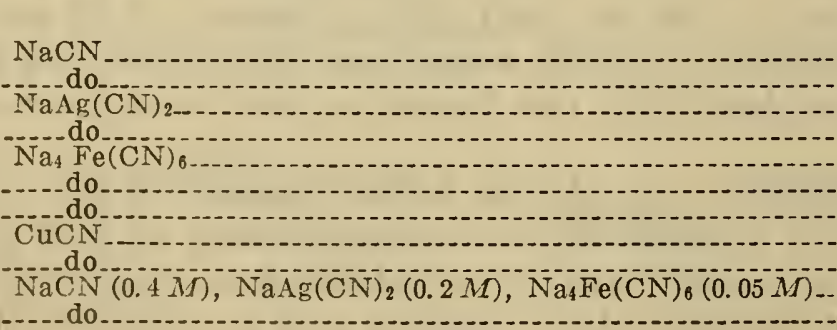 & $\begin{array}{l}g \\
0.1148 \\
.1112 \\
.1999 \\
.2006 \\
.2062 \\
.2081 \\
.2084 \\
.2089 \\
.2081 \\
.3006 \\
.2251\end{array}$ & $\begin{array}{r}g \\
0.1145 \\
.1109 \\
.1988 \\
.1994 \\
.2022 \\
.2039 \\
.2046 \\
.2065 \\
.2057 \\
.2988 \\
.2242\end{array}$ & $\begin{array}{r}\text { Per cent } \\
-0.26 \\
-. .27 \\
-.55 \\
-. .60 \\
-1.94 \\
-2.02 \\
-1.82 \\
-1.15 \\
-1.15 \\
=-.60 \\
-.40\end{array}$ \\
\hline
\end{tabular}

Typical results obtained by this method are given in Table 6. For $\mathrm{NaCN}$ and $\mathrm{NaAg}(\mathrm{CN})_{2}$, the major bath constituents, good recovery of cyanide is obtained The results of separate determinations of the minor constituents, such as $\mathrm{Na}_{4} \mathrm{Fe}(\mathrm{CN})_{6}$ and $\mathrm{CuCN}$, were slightly low. Since these substances normally represent only a small fraction of the total cyanide present in a silver bath, this error is not 
serious. The data for a synthetic plating solution show that 99.5 per cent of the total cyanide was recovered.

\section{TOTAL EFFECTIVE CYANIDE}

Among the constituents of the silver-plating bath the ferrocyanide is the most stable on electrolysis, and it is at least doubtful whether it has any marked effects upon the operation of the baths or the character of the deposits. For certain purposes it may therefore be desirable to determine what may be designated as the "total effective cyanide"; that is, the total content of the CN radical exclusive of that present as ferrocyanide.

Titration with iodine was found satisfactory for the total effective cyanide in silver baths. This method is similar to that used by $\mathrm{H}$. Baines (15) for the determination of silver halides after they are dissolved in alkali cyanide. Iodine reacts with alkali cyanide according to equation 6 .

$$
\mathrm{KCN}+\mathrm{I}_{2}=\mathrm{KI}+\mathrm{CNI}
$$

If silver is also present, reaction 7 follows.

$$
\mathrm{KAg}(\mathrm{CN})_{2}+2 \mathrm{I}_{2}=\mathrm{KI}+\mathrm{AgI}+2 \mathrm{CNI}
$$

When a silver solution containing free cyanide is titrated, the appearance of a precipitate of $\mathrm{AgI}$ serves as the endpoint of reaction 6, and measures the free cyanide. The initial precipitation of silver iodide is more readily detected and more reliable in a relatively concentrated solution containing an added salt such as sodium chloride. The iodo-starch reaction may be used to show the endpoint of reaction 7 , provided the dilution is sufficient to plevent interference by the reddish color of cyanogen iodide. The total concentration of cyanide should be not more than about $0.002 M$ for the second titration, therefore the sample should be greatly diluted prior to the final end point.

When copper is present, it reacts approximately according to equation 8:

$$
\mathrm{K}_{2} \mathrm{Cu}(\mathrm{CN})_{3}+3 \mathrm{I}_{2}=2 \mathrm{KaI}+\mathrm{CuI}+3 \mathrm{CNI}
$$

The mercury complex is similarly decomposed:

$$
\mathrm{K}_{2} \mathrm{Hg}(\mathrm{CN})_{4}+4 \mathrm{I}_{2}=2 \mathrm{KI}+\mathrm{HgI}_{2}+4 \mathrm{CNI}
$$

The exact composition of these complexes is in doubt, and these reactions may not be correct. Ferrocyanide is only slowly oxidized by iodine, and as will be shown, it has little effect unless its concentration is high.

The iodine solution is unstable and must be frequently restandardized. This may be done against a standard alkali cyanide solution, or preferably a standard silver cyanide solution containing free cyanide. In the latter solution, the content of silver is more nearly constant than that of alkali cyanide. Hence by using such a solution and basing the standardization on the second step in the titration, reliable results are obtained.

$$
\text { 79688-31-11 }
$$


TABLE 7.-Effects of impurities on the determination of total effective cyanide with iodine. Solution $0.25 N$ in silver and $0.25 M$ in free cyanide

\begin{tabular}{|c|c|c|c|c|c|c|c|}
\hline \multirow{3}{*}{ Experiment No. } & \multicolumn{4}{|c|}{ Impurities } & \multicolumn{2}{|c|}{$\begin{array}{l}\text { Total effective } \\
\text { cyanide }\end{array}$} & \multirow{3}{*}{ Error } \\
\hline & \multicolumn{4}{|c|}{$\begin{array}{l}\text { Equivalent to concentration in plating } \\
\text { solution }\end{array}$} & \multirow{2}{*}{$\begin{array}{l}\text { Present } \\
\text { millimols }\end{array}$} & \multirow{2}{*}{$\begin{array}{c}\text { Found } \\
\text { millimols }\end{array}$} & \\
\hline & $\mathrm{Na}_{3} \mathrm{CO}_{3}$ & $\mathrm{Fe}$ & $\mathrm{Cu}$ & $\mathrm{Hg}$ & & & \\
\hline $1 \ldots$ & $9 / 1$ & $g / 1$ & $g / 1$ & $g / 1$ & & & Per cent \\
\hline (2.-. & & $\cdots$ & & & $\begin{array}{l}2.000 \\
2.000\end{array}$ & $\begin{array}{l}2.006 \\
2.006\end{array}$ & $\begin{array}{l}+.3 \\
+.3\end{array}$ \\
\hline 4 & & $\begin{array}{l}3.8 \\
7.5\end{array}$ & & & $\begin{array}{l}2.000 \\
2.000\end{array}$ & $\begin{array}{l}2.004 \\
2.008\end{array}$ & $\begin{array}{r}+.2 \\
+.4\end{array}$ \\
\hline 6- & 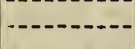 & 15.1 & 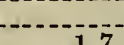 & - & 2. 000 & 2.028 & $\begin{array}{r}+1.4 \\
+4\end{array}$ \\
\hline 8 & $\ldots$ & - & $\begin{array}{l}\text { 3. } 0 \\
\text { 3. }\end{array}$ & 烈 & $\begin{array}{l}1.093 \\
1.993\end{array}$ & $\begin{array}{l}2.095 \\
2.025\end{array}$ & $\begin{array}{r}+.4 \\
+1.6\end{array}$ \\
\hline $9 \ldots$ & & & 4.4 & -18 & $\begin{array}{l}1.903 \\
1.658\end{array}$ & 1. 944 & +2.1 \\
\hline & & & & 0 & $\begin{array}{l}1.658 \\
1.658\end{array}$ & $\begin{array}{l}1.658 \\
1.656\end{array}$ & 0 \\
\hline & & & 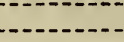 & 7.2 & 1. 658 & 1. 654 & -.2 \\
\hline
\end{tabular}

In Table 7 are shown the results obtained by titrating with iodine a known amount of alkali cyanide to which was added a definite

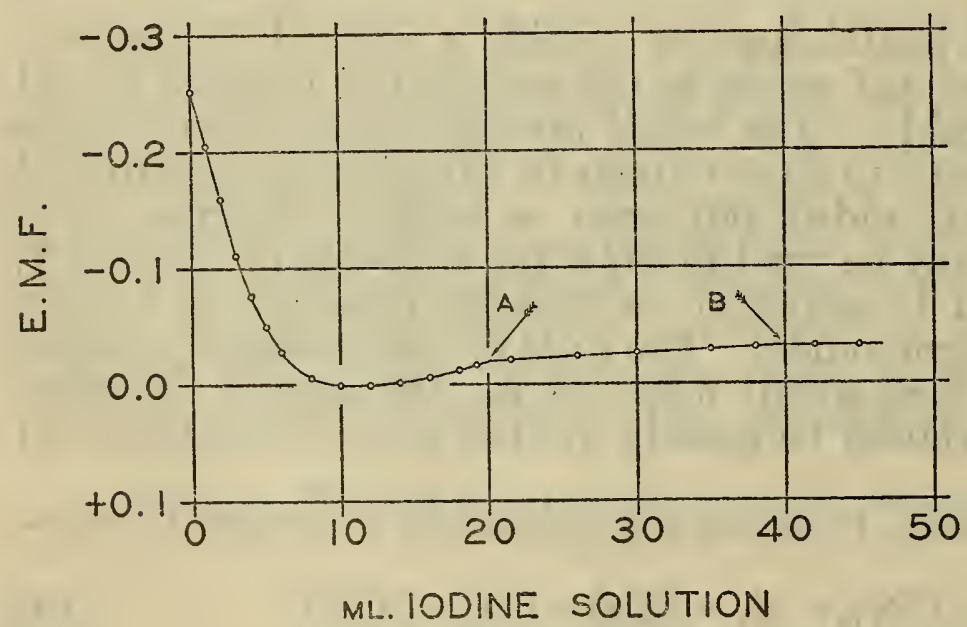

FIGURE 4.-Electrometric titration of silver cyanide solution with iodine

$A$, Initial precipitation of silver iodide, the end point for the titration of free cyanide.

$B$, Iodo-starch reaction, the end point for titration of total cyanide. amount of silver nitrate and the designated amounts of the specified impurities. The amounts of cyanide introduced with the copper and mercury were included. in that "present," but not the cyanide contained in the ferrocyanide. The results show that large amounts of carbonate have no effect. Relatively high concentrations of iron or copper produce appreciable errors. Small amounts of mercury have no marked effect, but very large amounts of mercury or copper entirely obscure the end point. The method therefore does not possess high accuracy in excessively contaminated solutions.

The iodine titration of cyanide was also followed electrometrically with a silver electrode, with the results shown in Figure 4. The solution contained two equivalents of free cyanide for one of silver. The visible end points of the two reactions occurred at the points $A$ and $B$, at which the inflections are not sufficiently sharp to accurately define the reactions. In the first portion of the curve the silver ion activity reached a maximum when about half the free cyanide was titrated. This behavior probably represents the formation of some complex between the argentocyanide ion and iodine. 


\section{SILVER}

\section{A. SEPARATION FROM THE CYANIDE}

Most methods for the determination of silver (except the electrolytic method) necessitate the separation of the silver from the cyanide. This can be accomplished either by precipitation of the silver or by decomposition of the cyanide solution.

(1) Precipitation of Silver.- (a) As sulphide.-Silver can be precipitated by the addition of ammonium sulphide to the cyanide solution. This procedure separates it not only from the cyanide, but also from ferrocyanide and metallic impurities, excepting mercury which also precipitates as sulphide. This method is described by Brook and Holmes (16), who ascribe it to Wright (17). Coagulation and complete precipitation of the silver sulphide are favored by boiling the ammoniacal solution. In this boiling, ammonium cyanide is volatilized (18). The silver sulphide can then be filtered out, washed, and dissolved in nitric acid to prepare it for titration.

(b) As silver.-Metallic silver can be precipitated by boiling the solution with pure granulated zinc, Clevenger (19). The precipitate, which contains the silver and excess of zinc, is then dissolved in nitric acid.

(2) Decomposition of the Cyanide.-When sulphuric acid is added to the cyanide solution silver cyanide is precipitated and hydrocyanic acid is evolved. The operation should therefore be conducted with very good ventilation. On evaporation the silver cyanide slowly dissolves. This dissolution can be hastened by adding initially a volume of concentrated sulphuric acid equal to twice the volume of plating solution. When commercial cyanide solutions are evaporated to fumes with sulphuric acid, darkening usually occurs. This disappears on the addition of a few milliliters of concentrated nitric acid and reevaporation to fumes. After cooling, the residue is dissolved in water. The resulting solution contains sulphates of all the metals present in the original bath.

\section{B. DETERMINATION OF SILVER}

(1) Volmard Titration.- The details of this well-known method (20) are discussed by Hillebrand and Lundell (21). The solution of silver nitrate or silver sulphate obtained by any of the above procedures is titrated with thiocyanate solution, using ferric alum as the indicator. The thiocyanate is standardized against silver nitrate. The presence of filter paper remaining from the solution of the silver or silver sulphide precipitate is unobjectionable. Usually it is preferable for high accuracy to treat the silver nitrate sample used for standardization in the same way as the plating solution. If small amounts of mercury are present, they will be included in this titration.

(2) Precipitation as Silver Chloride.- Silver chloride can be precipitated by the addition of hydrochloric acid to the silver solution obtained by any of the above methods. It can then be weighed or dissolved in standard cyanide and the excess cyanide determined by the Liebig titration, preferably with iodide present. It can also be determined after solution in cyanide, by titration with iodine (15) as described above. In the latter procedure it is not necessary to standardize the alkali cyanide, as the silver is equivalent to the combined cyanide as determined in the second part of the titration. 
(3) Electrolytic Determination.-Silver can be directly deposited from a diluted sample of the plating solution, to which additional cyanide has been added.

\section{COMPARISON OF METHODS}

In Table 8 are shown the results obtained by some of the above procedures upon a synthetic plating solution containing the usual impurities. These results show that all of the methods are sufficiently accurate for control, though the electrolytic method gives slightly low results. The choice of procedure is therefore largely one of expediency. The Volhard titration is almost invariably used in the industry. Decomposition with acid is preferable to the sulphide precipitation because no filtration is required.

TABLE 8.-Determination of silver in synthetic contaminated silver-plating solutions

\begin{tabular}{|c|c|c|c|c|c|}
\hline \multirow{2}{*}{$\begin{array}{c}\text { Experiment } \\
\text { No. }\end{array}$} & \multirow{2}{*}{ Separation } & \multirow{2}{*}{ Determination } & \multicolumn{3}{|c|}{ Silver } \\
\hline & & & Present & Found & Error \\
\hline $\begin{array}{l}7 \\
10 \\
11\end{array}$ & 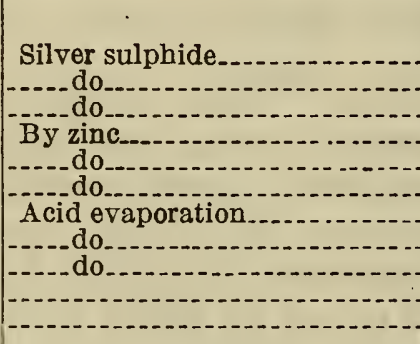 & 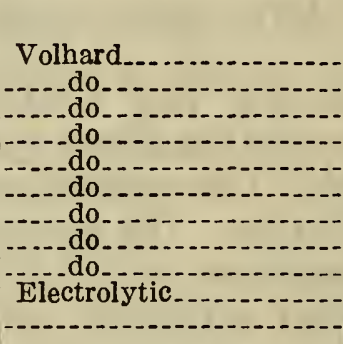 & $\begin{array}{l}8 \\
0.5016 \\
.5016 \\
.5016 \\
.3010 \\
.3210 \\
.3411 \\
.5016 \\
.5016 \\
.5016 \\
.4963 \\
.4961\end{array}$ & $\begin{array}{l}g \\
0.5026 \\
.4999 \\
.5023 \\
.3011 \\
.3213 \\
.3407 \\
.5016 \\
.5016 \\
.5015 \\
.4941 \\
.4932\end{array}$ & $\begin{array}{c}\text { Per cent } \\
+0.20 \\
-.34 \\
+.14 \\
+.03 \\
+.10 \\
-.12 \\
0 \\
0 \\
-.02 \\
-.44 \\
-.58\end{array}$ \\
\hline
\end{tabular}

3. CARBONATE

\section{A. BARIUM CARBONATE METHOD}

The usual method for determining carbonate in cyanide solutions is to precipitate and filter out barium carbonate and titrate it with acid, with methyl orange as indicator. Brook and Holmes (16) recommend barium cyanide as the precipitant, but experiments have shown that barium chloride or nitrate is equally satisfactory. As the alkaline solutions readily absorb carbon dioxide, the precipitation and filtration should be done as rapidly as possible. Operation in a $\mathrm{CO}_{2}$-free atmosphere is unnecessary except for very high accuracy. As shown in Table 9, the presence of ferrocyanide causes no significant error.

TABLE 9.-Determination of carbonate in synthetic contaminated silver-plating solutions

\begin{tabular}{|c|c|c|c|c|c|}
\hline \multirow{2}{*}{ Experiment No. } & \multirow{2}{*}{ Method } & \multirow{2}{*}{ Iron } & \multicolumn{3}{|c|}{$\mathrm{NaCO}_{3}$} \\
\hline & & & Present & Found & Error \\
\hline & $\mathrm{BaC}$ & $g / l$ & 0.4710 & 0.4714 & $\begin{array}{l}\text { Per cent } \\
+0.09\end{array}$ \\
\hline & - do & 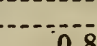 & $\begin{array}{l}.4669 \\
.4740\end{array}$ & .4685 & $\begin{array}{r}+.34 \\
+30\end{array}$ \\
\hline - & Direct titration. & 0.8 & .9320 & $\begin{array}{l}.4154 \\
.9340\end{array}$ & $\begin{array}{r}+.30 \\
+.21\end{array}$ \\
\hline 5 & do do........ & & .9198 & .9242 & +.48 \\
\hline ( & 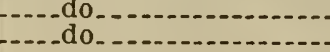 & .8 & $\begin{array}{l}.9269 \\
.9159\end{array}$ & $\begin{array}{l}.9231 \\
.9146\end{array}$ & $\begin{array}{l}-.41 \\
-.14\end{array}$ \\
\hline
\end{tabular}




\section{B. TITRATION AFTER ADDITION OF SILVER NITRATE}

Silver-plating solutions have a $\mathrm{pH}$ of about 11 , caused by the hydrolysis of the free cyanide as well as of carbonate. If silver nitrate is added to a solution containing no carbonate until the free cyanide is removed (Liebig titration) the resulting argentocyanide has a $\mathrm{pH}$ of about 7. Therefore any residual alkalinity in a plating solution similarly treated is due to carbonate (or less commonly to free alkali). As shown by Clennell (22), it is therefore possible to titrate the carbonate with acid, after completing the Liebig titration (conducted with or without iodide). Phenolphthalein is used as the indicator, to avoid reducing the $\mathrm{pH}$ below 7, where the argentocyanide would decompose. The titration therefore represents the conversion of carbonate to bicarbonate. F. Muhlert (23) modified the Clennell method by adding sufficient silver nitrate to precipitate all the cyanide, filtering out the silver cyanide, and titrating the carbonate. This method has no obvious advantages.

As shown in Table 9, the direct titration yields satisfactory results, even on contaminated solutions. As it is simpler and more rapid than the barium carbonate precipitation, it is preferable for control purposes.

\section{CHLORIDE}

The determination of chloride in alkali cyanide solutions is reviewed by Polstorff and Meyer (24). The method of W. Borchers (25) depends upon the decomposition of silver cyanide by concentrated nitric acid and the formation of insoluble silver chloride. When nitric acid is added to a silver-plating solution, a mixture of silver cyanide and chloride is first precipitated. When the solution is boiled the silver cyanide slowly dissolves and leaves a precipitate of silver chloride. In order that this shall include all the chloride present in the bath the silver must be in excess. This is usually the case, but for a solution that is high in chlorides it is advisable to add silver nitrate. The silver chloride can then be weighed or titrated by methods described above. As shown in Table 10 the results by this method are usually about 1 per cent low for contaminated solutions. This indicates that under the conditions used a small amount of the silver chloride is decomposed by the boiling nitric acid.

TABLE 10.-Determination of chloride in synthetic contaminated silver-plating solutions (containing $27 \mathrm{~g} / \mathrm{l} \mathrm{Na}_{2} \mathrm{CO}_{3}$ and $52 \mathrm{~g} / \mathrm{l} \mathrm{Na} \mathrm{F}_{4} \mathrm{~F}(\mathrm{CN})$ 。

\begin{tabular}{|c|c|c|c|c|}
\hline \multirow{2}{*}{ Method of separation } & \multirow{2}{*}{ Determination } & \multicolumn{3}{|c|}{ Sodium chloride } \\
\hline & & Present & Found & Error \\
\hline $\begin{array}{r}\text { Borchers.... } \\
\text { Do..... } \\
\text { Do } \\
\text { Alternate... } \\
\text { Do..... } \\
\text { Do..... }\end{array}$ & 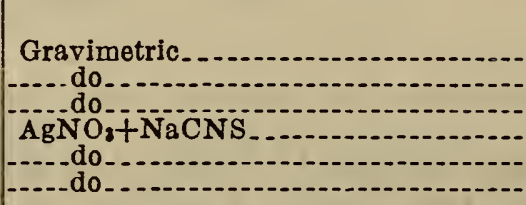 & $\begin{array}{l}0 . \\
0.2414 \\
.2439 \\
.2398 \\
.3664 \\
.3664 \\
.3664\end{array}$ & $\begin{array}{l}g \\
0.2376 \\
.2321 \\
.2367 \\
.3748 \\
.3730 \\
.3727\end{array}$ & $\begin{array}{r}\text { Per cent } \\
-1.6 \\
-1.2 \\
-1.3 \\
+2.3 \\
+1.8 \\
+1.7\end{array}$ \\
\hline
\end{tabular}

A new procedure for separating the chloride from the other constituents of the bath was investigated. In brief, the method involves (a) removal of silver as sulphide, (b) decomposition of the cyanide 
by boiling the ammoniacal solution, and $(c)$ precipitation of the ferrocyanide by the addition of a manganous salt. Qualitative tests showed that manganous ferrocyanide can be filtered and washed satisfactorily, while most of the other insoluble ferrocyanides are colloidal. The addition of manganous sulphate removes carbonate as well as ferrocyanide. The chloride may be determined in the resultant filtrate by numerous methods. Probably the most convenient of these is to acidify and titrate with silver nitrate, either directly with chromate indicator or by back titration of excess silver with thiocyanate.

Table 10 shows that the results are approximately correct though somewhat high for badly contaminated solutions. The method probably warrants further study.

\section{IRON, COPPER, AND MERCURY}

If the original plating solution is evaporated with sulphuric acid and the silver is removed as chloride, the filtrate contains the iron, copper, and mercury as sulphates. If silver is precipitated as sulphide the mercury accompanies it, and the filtrate which contains the iron and copper can then be decomposed with acid.

After the metals are obtained as sulphates, the usual methods of separation and determination can be applied. For example iron can be precipitated with ammonia and determined gravimetrically or volumetrically. The copper can be determined in the filtrate either volumetrically or electrolytically.

Mercury is best determined in the ammonium sulphide precipitate containing also the silver sulphide. The precipitate is treated with potassium hydroxide and ammonium sulphide, which mixture dissolves the mercuric sulphide. The silver sulphide is filtered out, and the mercuric sulphide is reprecipitated by boiling the filtrate with ammonium nitrate. The precipitate is filtered on a weighed Gooch crucible, washed successively with water, alcohol, carbon disulphide and ether, dried at $110^{\circ} \mathrm{C}$. and weighed as $\mathrm{HgS}$.

TABLE 11.-Determination of iron, copper, and mercury in synthetic contaminated silver-plating solutions

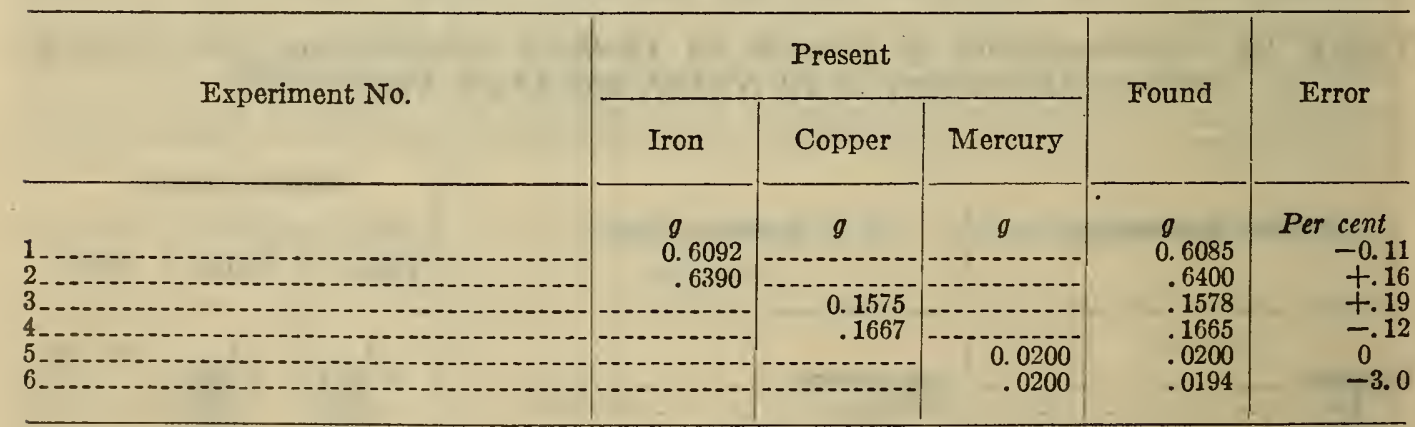

Table 11 gives typical results obtained for these metals in synthetic silver solutions. For the small amount of mercury present the three per cent error reported in one determination was equivalent to only $0.6 \mathrm{mg}$ of $\mathrm{Hg}$. Evidently the methods described meet all the usual requirements for the determination of these impurities. 


\section{AMMONIA}

Ammonia is formed in cyanide plating baths by the decomposition of alkali cyanide either through hydrolysis or oxidation, represented respectively by equations 10 and 11 .

$$
\begin{gathered}
\mathrm{KCN}+2 \mathrm{H}_{2} \mathrm{O}=\mathrm{HCOOK}+\mathrm{NH}_{3} \\
2 \mathrm{KCN}+2 \mathrm{H}_{2} \mathrm{O}+2 \mathrm{KOH}+\mathrm{O}_{2}=2 \mathrm{~K}_{2} \mathrm{CO}_{3}+2 \mathrm{NH}_{3}
\end{gathered}
$$

No quantitative data are available concerning the extent to which ammonia exists in commercial plating baths, or the rôle which it plays in electrodeposition.

Ćlennell (11) refers to a method of Bettel (26) for determining ammonia in cyanide solutions, but does not comment on its accuracy. This method involves complete precipitation of cyanogen compounds with silver, filtration, and distillation of the solution after the addition of a few drops of acid. The method appears complicated and of doubtful accuracy. In the course of this work a simple and accurate method has been developed which may be applied to cyanide plating solutions.

In an attempt to determine ammonia by direct distillation it was found that reaction 10 proceeds so rapidly at the boiling temperature that an appreciable amount of ammonia is formed during the distillation. An effort was then made to carry the ammonia over in a stream of air, but at either $25^{\circ} \mathrm{C}$. or $50^{\circ} \mathrm{C}$. this procedure was found to give incomplete recovery.

Preliminary experiments showed that the argentocyanide complex formed when silver nitrate is added to alkali cyanide (equation 1) is stable on boiling. It therefore seemed possible to determine ammonia present in alkali cyanide solution by "fixing" the free cyanide with silver nitrate and, after the addition of alkali, distilling into standardized acid and titrating the excess of the acid.

TABLE 12.-Determination of ammonia by distillation after addition of $\mathrm{AgNO}$ and $\mathrm{NaOH}$

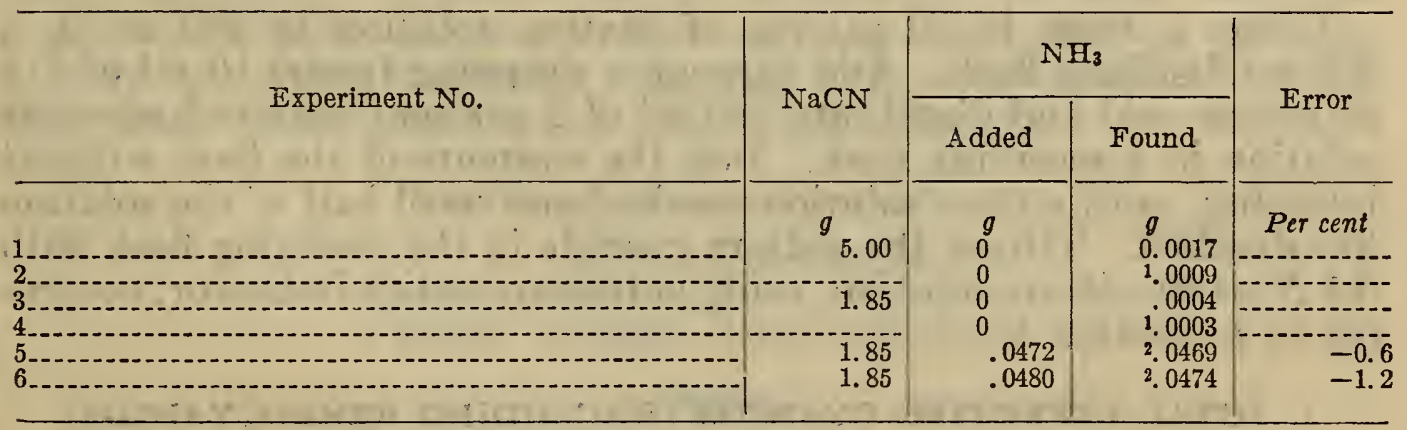

1 Second distillation of preceding solution after adding water.

2 After deducting blank of $0.0004 \mathrm{~g}$.

Table 12 shows that this method is satisfactory with moderate concentrations of cyanide. Blank distillations were first made on a $5 \mathrm{~g}$ and a $1.85 \mathrm{~g}$ sample of sodium cyanide, the latter amount being equivalent to $50 \mathrm{ml}$ of a typical plating solution. The fact that a higher blank was obtained with $5 \mathrm{~g}$ of $\mathrm{NaCN}$, and that in each case a small blank was obtained on a second distillation, indicates that there may be slight decomposition of the double cyanide, which is, however, negligible for the usual concentrations employed. 
Part of the blank might be due to a trace of the solution being carried over as spray, although precautions to prevent this were used. Any significant error from this source would be indicated by the appearance of turbidity in the distillate, which would be cause for rejecting the determination.

The results for known small amounts of ammonia are very satisfactory. An old commercial silver-plating solution to which no ammonia had ever been added was analyzed by this method and found to contain $0.58 \mathrm{~g} \mathrm{NH}_{3}$ per liter, equivalent to $0.034 \mathrm{~N}$. Further observations will be required to determine whether this concentration is typical or significant. Pan (27) has recently advised the addition of ammonia to silver baths. The above method for determining ammonia is probably applicable to other cyanide plating solutions, such as those of copper and brass.

\section{RECOMMENDED PROCEDURES}

The following explicit directions for the various determinations refer especially to the control of commercial plating solutions that may contain any of the usual impurities. To avoid confusion, only one method is described for each constituent. This selection is based on convenience and reliability as judged from the above experiments.

\section{FREE CYANIDE}

To a $20 \mathrm{ml}$ sample of the plating solution add $0.1 \mathrm{~g}$ of potassium iodide (or $0.2 \mathrm{~g}$ for badly contaminated solutions). Dilute to 250 $\mathrm{ml}$ and titrate with $0.1 \mathrm{~N}$ silver-nitrate solution. The end point of the titration is the first appearance of opalescence, best observed with a black background.

\section{$1 \mathrm{ml} 0.1 \mathrm{NAgNO}_{3} \cong 0.00980 \mathrm{~g} \mathrm{NaCN}$ or $0.01302 \mathrm{~g} \mathrm{KCN}$}

\section{TOTAL CYANIDE}

Dilute a fresh $10 \mathrm{ml}$ sample of plating solution to $250 \mathrm{ml}$ in a $500 \mathrm{ml}$ distilling flask. Add through a dropping funnel $10 \mathrm{ml}$ of $1: 1$ sulphuric acid and distill into $100 \mathrm{ml}$ of 2 per cent sodium-hydroxide solution in a receiving flask. Boil the contents of the flask without bumping, until a clear solution results ${ }^{3}$ and until half of the solution has distilled. Titrate the sodium cyanide in the receiving flask with $0.1 \mathrm{~N}$ silver-nitrate solution, using potassium iodide indicator, according to procedure 1 .

\section{TOTAL EFFECTIVE CYANIDE (EXCLUDING FERROCYANIDE)}

Dilute $50 \mathrm{ml}$ of the plating solution to $500 \mathrm{ml}$ in a graduated flask. To a $25 \mathrm{ml}$ aliquot $(2.5 \mathrm{ml}$ of the original) add $50 \mathrm{ml}$ of a 10 per cent sodium-chloride solution containing $2 \mathrm{ml}$ of concentrated ammonium hydroxide per liter, and titrate with $0.1 \mathrm{~N}$ iodine solution to the first visible turbidity. The volume of iodine consumed is proportional to the free cyanide.

Dilute the partially titrated sample to about 1 liter, add $5 \mathrm{ml}$ of starch solution ( 0.5 per cent), and continue the titration with iodine

If chloride is present, however, a permanent residue of $\mathrm{AgCl}$ will be observed. 
until a faint but permanent blue color is formed. This second volume of iodine solution is proportional to the combined cyanide, and the sum is equivalent to the "total effective cyanide."

\section{$1 \mathrm{ml} 0.1 \mathrm{~N} \mathrm{I}_{2} \approx 0.00245 \mathrm{~g} \mathrm{NaCN}$ or $0.00326 \mathrm{~g} \mathrm{KCN}$}

\section{SILVER}

Treat $10 \mathrm{ml}$ of plating solution with $20 \mathrm{ml}$ of concentrated sulphuric acid. Evaporate to fumes of sulphuric acid in a well-ventilated hood. Add a few drops of concentrated nitric acid if necessary to hasten decomposition of organic matter and reevaporate to fumes; cool, dilute to $150 \mathrm{ml}$, and warm until all solids are dissolved. Add $3 \mathrm{ml}$ of saturated ferric ammonium alum solution and titrate with $0.1 \mathrm{~N}$ potassium thiocyanate to the appearance of a pink coloration.

$$
1 \mathrm{ml} 0.1 N \mathrm{KCNS} \approx 0.01079 \mathrm{~g} \mathrm{Ag}
$$

\section{CARBONATE}

To the solution resulting from the Liebig titration for free cyanide (procedure 1) add a few drops of phenolphthalein solution and titrate with $0.5 N$ hydrochloric acid until the pink color is completely discharged.

\section{$1 \mathrm{ml} 0.5 \mathrm{~N} \mathrm{HCl} \approx 0.0530 \mathrm{~g} \mathrm{Na}_{2} \mathrm{CO}_{3}$ or $0.0691 \mathrm{~g} \mathrm{~K}_{2} \mathrm{CO}_{3}$}

\section{CHLORIDE}

To $10 \mathrm{ml}$ of silver-plating solution add $20 \mathrm{ml}$ of concentrated nitric acid under a hood. (If the solution is high in chloride, add an excess of silver nitrate before adding the acid.) Heat until decomposition is complete, as indicated by the precipitate becoming nearly white. Continue the digestion for one-half hour, keeping the volume constant by the addition of concentrated nitric acid. Dilute to $75 \mathrm{ml}$, make alkaline with concentrated ammonium hydroxide, and filter out the ferric hydroxide. Dissolve the ferric hydoxide in nitric acid and reprecipitate with ammonia; filter and combine the two filtrates. Acidify the combined filtrates with nitric acid, filter the silver chloride on a tared Gooch crucible, dry, and weigh as $\mathrm{AgCl}$.

$$
\text { Factor } \begin{aligned}
\mathrm{AgCl} & \rightarrow \mathrm{NaCl}=0.408 \\
\mathrm{AgCl} & \rightarrow \mathrm{KCl}=0.520
\end{aligned}
$$

\section{IRON, COPPER, AND MERCURY}

\section{A. IRON}

Decompose a $10 \mathrm{ml}$ sample of plating solution with $20 \mathrm{ml}$ of concentrated sulphuric acid. Evaporate to fumes in a hood. If necessary, add a little concentrated nitric acid to destroy organic matter and reevaporate to fumes; cool, dilute to $150 \mathrm{ml}$, and warm to obtain complete solution of metal salts. Filter out any silica. Make the solution slightly alkaline with ammonium hydroxide, heat to coagulate the precipitate, and filter out the ferric hydroxide. (A blue filtrate indicates the presence of copper.) Dissolve the ferric hydroxide in hot $1: 1$ hydrochloric acid. Reprecipitate with ammonia, filter, and redissolve the ferric hydroxide. 
Dilute the ferric-chloride solution to $50-75 \mathrm{ml}$, heat almost to boiling, and reduce the iron with stannous chloride, ${ }^{4}$ added drop by drop, with only one or two drops in excess. Cool and add quickly $20 \mathrm{ml}$ of a saturated mercuric-chloride solution and let stand three minutes. Add $15 \mathrm{ml}$ of phosphoric-hydrochloric-acid mixture, ${ }^{5}$ three drops diphenylamine indicator, ${ }^{6}$ and titrate with $0.1 \mathrm{~N}$ bichromate solution. At the end point the solution changes from green to bluish green and finally to an intense violet blue with one drop of bichromate.

\section{$1 \mathrm{ml} 0.1 \mathrm{~N} \mathrm{~K}_{2} \mathrm{Cr}_{2} \mathrm{O}_{7} \approx 0.00558 \mathrm{~g} \mathrm{Fe}$}

\section{B. COPPER}

A blue filtrate from the iron separation (7-A) indicates the presence of copper. To $10 \mathrm{ml}$ of plating solution diluted to $100 \mathrm{ml}$ add $3 \mathrm{ml}$ of $6 \mathrm{~N}$ ammonium-sulphide solution. Heat almost to boiling, until the precipitate of silver sulphide has completely coagulated. Filter and evaporate the filtrate to about $10 \mathrm{ml}$. Cool and cautiously add $20 \mathrm{ml}$ of concentrated sulphuric acid, evaporate to fumes, cool, dilute to $150 \mathrm{ml}$, and warm to obtain complete solution. Heat to $60^{\circ}-70^{\circ} \mathrm{C}$. and electrolyze, using a platinum or copper gauze cathode and a platinum anode. Weigh as $\mathrm{Cu}$.

\section{MERCURY}

To a $20 \mathrm{ml}$ sample of plating solution diluted to $100 \mathrm{ml}$ add $5 \mathrm{ml}$ of $6 \mathrm{~N}$ ammonium-sulphide solution. Heat the solution until the sulphides completely coagulate. Filter and wash. Treat the precipitate with $100 \mathrm{ml}$ of $0.1 \mathrm{~N}$ sodium hydroxide and $1 \mathrm{ml}$ of ammonium sulphide. Digest on a steam bath for one-half hour. Filter and wash. To the filtrate add $10 \mathrm{ml}$ of 10 per cent ammonium-nitrate solution and warm; a black precipitate indicates the presence of mercury. Boil off the ammonia, filter on a tared Gooch crucible, wash with water, alcohol, carbon disulphide, and ether. Dry at $110^{\circ}$ C. and weigh as $\mathrm{HgS}$.

\section{Factor $\mathrm{HgS} \rightarrow \mathrm{Hg}=0.862$}

\section{AMMONIA}

Titrate a fresh $50 \mathrm{ml}$ sample of plating solution with $0.5 \mathrm{~N}$ silver nitrate, using potassium iodide according to procedure 1 . Dilute to $250 \mathrm{ml}$ in a $500 \mathrm{ml}$ Kjeldahl flask, add $10 \mathrm{ml}$ of 10 per cent sodiumhydroxide solution, and distill with a good trap into $50 \mathrm{ml}$ of $0.1 \mathrm{~N}$ hydrochloric acid which has been diluted to $125 \mathrm{ml}$ in the receiving flask. Boil the contents of the flask without bumping, until half of the solution has distilled. Titrate the residual acid in the receiving flask with $0.1 \mathrm{~N}$ sodium hydroxide, using methyl orange as indicator. The difference between the initial and final amounts' of hydrochloric acid corresponds to the ammonia.

\section{$1 \mathrm{ml} 0.1 \mathrm{~N} \mathrm{HCl} \approx 0.00170 \mathrm{~g} \mathrm{NH}$}

- $115 \mathrm{~g} \mathrm{SnCl}_{2} .2 \mathrm{H}_{2} \mathrm{O}$ dissolved in $170 \mathrm{ml} \mathrm{HCl}$ (s. g. 1.18) diluted to 1 liter and stored in a bottle containing a piece of pure tin.

$450 \mathrm{ml} / 1 \mathrm{H}_{3} \mathrm{PO}_{1}$ (s. g. 1.70) and $500 \mathrm{ml} / 1 \mathrm{HCl}$ (s. g. 1.18).

- 1 gram indicator in $100 \mathrm{ml} \mathrm{H}_{2} \mathrm{SO}_{4}$ (s. g. 1.84). 


\section{ACKNOWLEDGMENTS}

The author wishes to express his appreciation for the cooperation received from W. Blum, M. R. Thompson, and other associates at the National Bureau of Standards.

\section{REFERENCES}

1. J. Liebig, Ann., vol. 77, p. 102, 1851. J. Chem. Soc., vol. 4, p. 219, 1852.

2. F. C. Frary and R. E. Porter, Trans. Am. Electrochem. Soc., vol. 24, p. $271,1913$.

3. M. R. Thompson, B. S. Jour. Research, vol. 6, p. 1051, 1931.

4. I. M. Kolthoff and N. H. Furman, Potentiometric Titrations, John Wiley and Sons, New York, 1926.

5. W. D. Treadwell, Z. anorg. Chem., vol. 71, p. 223, 1911.

6. E. Müller and H. Lauterbach, ibid., vol. 121, p. 178, 1922.

7. Bodländer and Eberlein, ibid, vol. 39, p. 197, 1904.

8. R. Lucas, ibid., vol. 41, p. 193, 1904.

9. Böttger, Z. physik. Chem., vol. 56, p. 93, 1906.

10. G. Denigès, Ann. chim. phys. [7], vol. 6, p. 381, 1895.

11. J. E. Clennell, Chemistry of Cyanide Solutions, McGraw-Hill Book Co., New York, 1910.

12. W. J. Sharwood, J. Am. Chem. Soc., vol. 19, p. 400, 1897.

13. E. B. Sanigar, Trans. Am. Electrochem. Soc., vol. 58, p. 435, 1930.

14. H. E. Williams, J. Soc. Chem. Ind., vol. 31, p. 468, 1912.

15. H. Baines, J. Chem. Soc., p. 2037, 1929.

16. G. B. Brook and L. W. Holmes, Trans. Faraday Soc., vol. 16, p. 527, 1920-21.

17. H. C. Wright, Proc. Sheffield Soc. of App. Met., 1912.

18. J. E. Clennell, the Cyanide Handbook, McGraw-Hill Book Co., New York, 1910.

19. G. H. Clevenger, Eng. Min. J., vol. 95, p. 892, 1913.

20. J. Volhard, J. prakt. Chem., vol. 9, p. 217, 1874. Ann. vol. 190, p. 1, 1878.

21. W. F. Hillebrand and G. E. F. Lundell, Applied Inorganic Analysis, 1st ed., John Wiley \& Sons, New York, 1929.

22. J. E. Clennell, Chem. News, vol. 71, p. 93, 1895.

23. F. Muhlert, Z. angew. Chem., vol. 34, p. 447, 1921.

24. K. Polstorff and H. Meyer, Z. anal. Chem., vol. 51, p. 601, 1912.

25. W. Borchers, ibid., vol. 22, p. $92,1883$.

26. Bettel, J. Chem. and Met. Soc., South Africa, vol. 1, p. 168, 1898.

27. L. C. Pan, Trans. Electrochem. Soc., vol. 59, preprint, 1931.

Washington, August 11, 1931. 